\title{
Niveles de malnutrición por exceso en la población atacameña de una región rural y una urbana en el norte de Chile
}

\author{
Antonio Zapata ${ }^{1}$, Trinidad Madrid ${ }^{1}$, Franco Zapata ${ }^{2}$, Claudia Fernández ${ }^{3}$, Pabla Flores ${ }^{3}$. \\ 1 Residente de Medicina Interna Hospital Clínico UC \\ 2 Estudiante de Medicina, Universidad de Concepción \\ 3 Enfermera Universitaria COMDES, Calama.
}

Introducción: El sobrepeso y la obesidad son cada vez más prevalentes y colaboran a mayor riesgo cardiovascular. No existen estudios sobre estas patologías en la población atacameña, (tercer grupo más numeroso entre las etnias originarias en Chile).

Objetivo: Evaluar niveles de sobrepeso y obesidad de la población de etnia atacameña y comparar el estado nutricional de atacameños ubicados en una región Rural (Alto el Loa), y una urbana (Calama).

Metodología: Se analizaron exámenes de medicina preventiva del adulto (EMPA) de postas rurales de Alto El Loa, y del Centro Comunitario de Salud Familiar (CECOF) de Calama en los años 2007 y 2008. Se seleccionaron pacientes con ambos apellidos de origen atacameño, quienes además tuvieran padres y abuelos (maternos y paternos) con apellidos del mismo origen. Se midió peso, talla, IMC, circunferencia de cintura (CC), presión arterial (PA), glicemia y colesterol plasmáticos. Resultados: 43 sujetos de Alto el Loa (AL) y 98 sujetos de Calama cumplieron criterios de selección. En el grupo Alto El Loa el peso fue normal en 30\% de los sujetos, hubo sobrepeso en $46,5 \%$ y obesidad en $23,5 \%$. Los valores correspondientes para el grupo de Calama fueron $25 \%, 42,7 \%$ y $32,3 \%$, respectivamente (N.S.). Al comparar ambos grupos, solo hubo diferencias significativas en colesterol plasmático ( $163 \mathrm{mg} / \mathrm{dl} \mathrm{AL}$ vs 188 $\mathrm{mg} / \mathrm{dl}$ Calama) y CC en hombres (110 cm AL vs $99,3 \mathrm{~cm}$ Calama) y mujeres (113cm AL vs $90,6 \mathrm{~cm}$ Calama).

Conclusión: Ambos grupos de atacameños presentaron más de un $70 \%$ de malnutrición por exceso. Solo hubo diferencias entre ambos grupos en CC y colesterol total. Destaca la CC mayor en Alto El Loa (zona de menor mestizaje), que sugieren un genotipo atacameño con tendencia a mayores niveles de grasa abdominal.

Correspondencia:

Dr. Antonio Zapata.

Pontificia Universidad Católica de Chile

Email: amzapatap@gmail.com 


\section{Malnutrition causing overweight and obesity in urban and rural populations of "atacameños" from northern Chile}

Background: Overweight and obesity are cardiovascular risk factors becoming more prevalent in later years. There are no studies related to this problem in the atacameña population, which is the third largest group among original inhabitants in Chile.

Aim: to evaluate prevalence of overweight and obesity in "atacameños" of northern Chile and to compare these findings in a rural (Alto el Loa) and an urban locations (Calama).

Methods: The data obtained from preventive medical examinations performed in primary care centers of Alto el Loan and Calama during 2007 and 2008 were used for the analysis. The subjects included had both paternal and maternal grand parents with "atacameños" surnames. Weigth, height, body mass index, waist circumference, blood pressure, blood glucose level and

\section{Introducción.}

La obesidad es una enfermedad cada vez mas prevalente, y rápidamente se está transformando en un problema nutricional a nivel mundial, considerándose la epidemia global del siglo XXI. En EE.UU, la prevalencia de obesidad en la población adulta (IMC $>30$ ), es cercana a un tercio de la población $(33,8 \%)^{1}$. En Chile, la prevalencia de sobrepeso en la población adulta es $39,3 \%$ y de obesidad $27,4^{2}$..

El rápido aumento del sobrepeso y la obesidad tienen gran importancia epidemiológica, considerando su carácter crónico y su estrecha relación con otras patologías que incrementan el riesgo de morbimortalidad, como son la diabetes mellitus, la hipertensión arterial y las dislipidemias. Ello puede relacionarse con mayor riesgo de enfermedades cardiovasculares, y con mayor frecuencia de ciertos cánceres ${ }^{3}$.

La obesidad se define como el exceso de tejido adiposo corporal. Si bien es difícil efectuar mediciones precisas del porcentaje real de grasa corporal, la medición del Índice de Masa Corporal (IMC) es una forma rápida y simple para evaluar la magnitud de la obesidad. IMC $>25 \mathrm{Kg} /$ $\mathrm{m} 2$ define el sobrepeso e IMC $>30 \mathrm{Kg} / \mathrm{m} 2$ es considerado indicador de obesidad. Existe correlación entre un mayor IMC y mayor riesgo de enfermedades cardiovasculares ${ }^{1,4}$. En Chile existen pocos estudios sobre la prevalencia de sobrepeso y obesidad en las etnias originarias. En parti- serum cholesterol were determined.

Results: 43 subjects from Alto el Loa and 98 subjects from Calama were included. Weight was normal in $30 \%$ of subjects from Alto el Loa; overweight was present in $46.5 \%$ and obesity in $23.5 \%$. Corresponding values for subjects from Calama were $25 \%, 42.7 \%$ and $32.3 \%$ (NS). The only significantly different variables were serum cholesterol $(163 \mathrm{mg} / \mathrm{dl}$ in Alto el Loa vs 188 $\mathrm{mg} / \mathrm{dl}$ in Calama) and waist circumference: $(110 \mathrm{~cm}$ in Alto el Loa vs $99,3 \mathrm{~cm}$ in Calama for males, and $113 \mathrm{~cm}$ in Alto el Loa vs $90.6 \mathrm{~cm}$ in Calama for women).

Conclusion: malnutrition leading to overweight and obesity affected $70 \%$ of "atacameños". Lower serum cholesterol levels and increased waist circumference suggest the presence of factors leading to accumulation of abdominal fat in the rural population.

Key words: risk factors, ethnic groups, obesity.

cular, es notoria la falta de información epidemiológica respecto de los atacameños (tercer grupo más numeroso entre las etnias originarias en Chile), considerando su importante presencia en la zona del Norte Grande de Chile, en particular en las localidades del altiplano.

El objetivo de este estudio fue evaluar los niveles de malnutrición por exceso en la población atacameña y comparar dos grupos de esta etnia provenientes de una localidad rural y otra urbana.

\section{Métodos}

Se analizaron exámenes de medicina preventiva del adulto (EMPA) de postas rurales de Alto El Loa, específicamente de las localidades de Chiu-Chiu, Lasana, Ayquina, Turi, Toconce, y Caspana, que se ubican a más de 2.000 mts sobre el nivel del mar, y en el Centro Comunitario de Salud Familiar (CECOF) de Calama (zona urbana), realizados en los años 2007 y 2008. Se seleccionaron sujetos con apellidos de origen atacameño, quienes además tuvieran padres y abuelos (maternos y paternos) con apellidos del mismo origen étnico. Las personas evaluadas asistieron voluntariamente a realizarse el examen de medicina preventiva, y no existió selección previa de los sujetos. Se analizaron los datos de 141 EMPA, 43 correspondientes a sujetos de Alto El Loa y 98 a residentes en la ciudad de Calama. Se evaluó peso, talla, edad, índice de masa corporal (IMC), circunferencia de cintura (CC), presión arterial 
(PA), glicemia y colesterol plasmáticos. Las mediciones antropométricas se realizaron con el individuo descalzo y con ropa ligera. La presión arterial se determinó con el individuo sentado y en reposo, con esfingomanómetro de mercurio, considerándose el promedio de dos mediciones, una realizada al inicio del examen y otra al final del mismo. El colesterol y glicemia plasmáticos se determinaron con muestras tomadas en ayuno, por métodos enzimáticos convencionales realizados en un mismo laboratorio (laboratorio clínico del Departamento de Salud de la Corporación Municipal de Desarrollo Social, de Calama). Las diferencias estadísticas fueron analizadas mediante la prueba de $\mathrm{t}$ de Student o Chi cuadrado con el programa estadístico SSPS.

\section{Resultados}

Se obtuvieron 43 EMPA de Alto el Loa y 98 EMPA de Calama correspondientes a sujetos con apellidos de origen atacameño. En los dos grupos se observó una mayor participación de mujeres. El promedio de edad de los individuos fue similar en ambos grupos. El grupo Alto El Loa presentó promedios de peso $65,9 \mathrm{~kg}$, e IMC 27,4, distribuidos de la siguiente forma: $30,4 \%$ peso normal, $46,5 \%$ sobrepeso y $23,1 \%$ obesidad. El grupo de Calama mostró promedios de peso 69,1 kg, e IMC 28,1 distribuidos en $25,1 \%$ peso normal, $42,7 \%$ sobrepeso y $32,2 \%$ obesidad. (Tablas 1 y 2).

Se compararon los resultados de los parámetros antropométricos y de laboratorios del grupo de la zona rural (Alto EL Loa) con los correspondientes de la zona urbana (Calama). Solo hubo diferencias significativas en colesterol total y $\mathrm{CC}$ en hombres y mujeres $(\mathrm{p}<0,05)$; no hubo diferencias al comparar distribución de peso, IMC, PA ni glicemia (Tabla 1).

\begin{tabular}{|c|c|c|c|}
\hline & $\begin{array}{c}\text { Total } \\
(n=141)\end{array}$ & $\begin{array}{l}\text { Alto El Loa } \\
(n=43)\end{array}$ & $\begin{array}{c}\text { Calama } \\
(n=98)\end{array}$ \\
\hline $\begin{array}{l}\text { Edad (años) } \\
\text { Peso (kg) } \\
\text { Talla (mts) } \\
\text { IMC (Kg/m2) } \\
\text { CC (cm) }\end{array}$ & $\begin{array}{l}59 \pm 11,0 \\
67,3 \pm 9,9 \\
1,53 \pm 0,08 \\
27,6\end{array}$ & $\begin{array}{l}58 \pm 10,5 \\
65,9 \pm 9,4 \\
1,54 \pm 0,08 \\
27,4\end{array}$ & $\begin{array}{c}60 \pm 11,3 \\
69,1 \pm 10,4 \\
1,56 \pm 0,10 \\
28,1\end{array}$ \\
\hline $\begin{array}{l}\text { hombres } \\
\text { mujeres }\end{array}$ & $\begin{array}{l}101,8 \pm 5,1 \\
97,1 \pm 5,7\end{array}$ & $\begin{array}{l}110 \pm 4,6 \\
113 \pm 5,3\end{array}$ & $\begin{array}{l}99,3^{*} \pm 5,4 \\
90,6^{*} \pm 6,0\end{array}$ \\
\hline $\begin{array}{l}\text { PAS (mmHg) } \\
\text { PAD (mmHg) } \\
\text { Colesterol plasmático } \\
\text { (mg/dl) } \\
\text { Glicemia plasmática } \\
\text { (mg/dl) }\end{array}$ & $\begin{array}{l}120 \pm 13,1 \\
74 \pm 9,9 \\
177,8 \pm 24,6 \\
100,3 \pm 15,2\end{array}$ & $\begin{array}{l}116 \pm 12,2 \\
74 \pm 9,4 \\
163 \pm 20,5 \\
100 \pm 14,3\end{array}$ & $\begin{array}{l}124 \pm 14,3 \\
74 \pm 10,0 \\
188^{*} \pm 26,8 \\
101,9 \pm 16,2\end{array}$ \\
\hline
\end{tabular}

${ }^{*} p<0,05$. CC: circunferencia de cintura; IMC índice de masa corporal, PAS presión arterial sistólica, PAD presión arterial diastólica.

\begin{tabular}{|cccc|}
\hline \multicolumn{5}{|c|}{$\begin{array}{c}\text { Tabla 2. Distribución de rangos de IMC en } \\
\text { Población Atacameña. }\end{array}$} \\
\begin{tabular}{|cccc} 
IMC (kg/ \\
m2)
\end{tabular} & $\begin{array}{c}\text { Total }(\boldsymbol{n}=141), \\
(\%)\end{array}$ & $\begin{array}{c}\text { Alto El } \\
\text { Loa, }(\%)\end{array}$ & $\begin{array}{c}\text { Calama, } \\
(\%)\end{array}$ \\
\hline $18,5-24,9$ & 27,62 & 30,4 & 25,1 \\
$25-29.9$ & 43,5 & 46.5 & 42.7 \\
$30-34,9$ & 21,85 & 16,2 & 25 \\
$35-39,9$ & 4,95 & 4.6 & 5.2 \\
$\geq 40$ & 2,08 & 2,3 & 2 \\
\hline
\end{tabular}

\section{Discusión.}

Nuestro estudio muestra una alta prevalencia de malnutrición por exceso en la población atacameña, con niveles de IMC $>25 \mathrm{~kg} / \mathrm{m} 2$ que sobrepasan el $70 \%$ en ambos grupos y niveles de obesidad cercanos al $25 \%$ de la población analizada. Además, en ambos grupos los promedios de circunferencia de cintura se presentan en rango de obesidad abdominal, tanto en hombres como en mujeres. En nuestro conocimiento, estos son los primeros datos que se publican en Chile sobre malnutrición por exceso en población de origen atacameño.

Al comparar los resultados de la muestra de atacameños con los valores obtenidos en la Encuesta Nacional de Salud Chilena del 2010 (ENS 2010), observamos que los niveles de sobrepeso y obesidad son mayores a los de la población general chilena. Dos tercios de las personas en la Encuesta Nacional de Salud Chilena del 2010 presentaban IMC >25, cifra que en la población atacameña del presente estudio alcanza a $73 \%$.

Interesantemente, llama la atención que las cifras de obesidad en nuestros dos grupos son mucho menores que las publicadas para otros grupos aborígenes chilenos. Al respecto, existen pocos estudios que evalúen la prevalencia de sobrepeso y obesidad en las poblaciones de las etnias originarias en Chile, y de éstos, la mayoría esta focalizado al análisis de la población de origen mapuche. Larenas, en 1985 publica los primeros datos de prevalencia de obesidad en la población mapuche de una comunidad rural en la IX región , en donde estimó, en la población mayor de 20 años, una presencia de obesidad de $17,2 \%$ en hombres y $61,9 \%$ en mujeres ${ }^{5}$.Pérez, en 1999, publica un porcentaje de obesidad de $62,9 \%$ en mujeres y $39,7 \%$ en hombres mapuches mayores de 25 años de localidades rurales de la IX región ${ }^{6}$.Berrios, en 1990, publica datos respecto a población mapuche urbana, en la que determina una prevalencia de obesidad de $55,2 \%$ en mujeres y $30,9 \%$ en hombres ${ }^{7}$. Respecto a los grupos aborígenes de la zona norte del país, en las publicaciones solo se hace referencia al grupo Aymará. Carrasco, en el año 2004, publica datos de población urbana Aymará, en donde registra 35,7\% de obesidad en hombres y $48,3 \%$ en mujeres ${ }^{8}$.

A diferencia de otros estudios similares, en nuestra población destaca que no se observaron diferencias importantes 
respecto del peso y del IMC promedio entre el grupo rural y el urbano. Ello puede sugerir una menor influencia de la carga ambiental en la prevalencia de sobrepeso y obesidad en ambos grupos. Tampoco hubo diferencias en los niveles de talla, presión arterial ni glicemia. El grupo de atacameños de la zona rural presentó mayor circunferencia de cintura y mayor nivel de colesterol plasmático que el grupo más urbano. En las publicaciones sobre poblaciones de etnias originarias chilena no se hace referencia a comparación de niveles de circunferencia de cintura. Solo Pérez et al, en 1999, en su estudio sobre prevalencia de obesidad, HTA y dislipidemia en grupos aborígenes rurales en Chile, se refiere a la medición de índice cintura cadera 6. El que los niveles de circunferencia de cintura sean más altos en la población atacameña rural, que probablemente presenta menos mestizaje, podría sugerir un genotipo atacameño con predisposición a mayores niveles de grasa abdominal.
Dentro de las limitaciones de nuestro estudio, podemos mencionar que las muestras de ambos grupos no son aleatorias, y el promedio de edad de ambos grupos fue superior a los 55 años, por lo que la población joven está probablemente subrepresentada. Una situación similar se observó en la menor proporción de hombres, quienes son más reticentes a concurrir a exámenes de control de salud. Los niveles de sobrepeso y obesidad en las poblaciones atacameñas estudiadas son preocupantes, no escapando a la realidad chilena. Deben instaurarse medidas de educación y tratamiento de este importante problema de salud pública, considerando su carácter crónico y su asociación a distintas enfermedades crónicas no transmisibles. Además, es importante tener presente que las diferentes etnias deben ser estudiadas en forma específica, dada las diferencias epidemiológicas que presentan respecto de la población chilena en general.

\section{Referencias:}

(1) www.cdc.gov/obesity revisado en Septiembre/2011

(2) Segunda Encuesta Nacional de Salud Chile 2009 - 2010 en www.minsal.gob.cl/portal/docs/page/minsalcl/g_home/submenu_portada_2011/ens2010.pdf

(3) CUEVAS A, REYES M. Lo último en diagnóstico y tratamiento de la obesidad: ¿Hay lugar aún para la terapia conservadora?. Rev. méd. Chile 2005;133:713-22.

(4) ARONNE,LJ.Classification of obesity and assessment of obesity-related health risks. Obes Res. 2002; 10: 105S-115S.

(5) LARENAS G, ARIAS G, ESPINOZAO, CHARLES M, LANDAETA O, VILLANUEVA S, et al. Prevalencia de diabetes mellitus en una comunidad Mapuche de la IX Región, Chile. Rev Méd Chile 1985; 113: 1121-5.

(6)

PÉREZ F, CARRASCO E, SANTOS JL, CALVILLÁN M, ALBALA C. Prevalencia de obesidad, hipertensión arterial y dislipidemia en grupos aborígenes rurales de Chile. Rev. méd. Chile 1999; 127:1169-75.

(7) BERRIOS X, JADUE L, ZENTENO J, ROSS MI, RODRÍGUEZ H. Prevalencia de factores de riesgo de enfermedades crónicas. Estudio en población general de la Región Metropolitana, 1986-1987. Rev Méd Chile 1990; 118: 597-604.

(8) CARRASCO EP, PÉREZ FB, ANGEL BB, ALBALA CB, SANTOS JL, LARENAS GY, et al. Prevalencia de diabetes tipo 2 y obesidad en dos poblaciones aborígenes de Chile en ambiente urbano. Rev. méd. Chile 2004; 132: 1189-97. 